\title{
Incomplete tooth fracture - proposal for a new definition
}

\author{
S. G. S. Ellis,'
}

\section{Many terms have been used to describe incomplete tooth fractures. This paper reviews them, discusses the clinical features of incomplete tooth fractures and proposes a clinically representative definition.}

\begin{abstract}
Terminology relating to incomplete 1 tooth fractures (ITFs) has received significant attention in the scientific literature for nearly half a century. ${ }^{1-16}$ This array of literature may be considered to be the result of a progressive increase in the knowledge of ITFs, however, no definition to date truly reflects the clinical issues. This article aims to highlight the characteristics of, and proposes a new definition for, ITF. No attempt is made to revisit the aetiology ${ }^{17}$ or the management issues ${ }^{9,11,17-33}$ of diagnosis, conservation techniques, endodontic and periodontic implications nor rationale for orthodontics, root resections or extraction. It is hoped that this paper will help clinicians understand and appreciate these fractures when considering diagnosis and treatment.
\end{abstract}

\section{The existing terminology}

Numerous terms and definitions have appeared in the dental literature relating to non-distinct fractures and cracks of teeth and are summarised chronologically in Figure 1. It is evident that they arose from difficulties with diagnosis, prognosis assessment and treatment. ${ }^{1-16}$ Cuspal fracture odontalgia, fissured fracture, incomplete tooth fracture, fissural fracture, crack lines and greenstick fractures were early descriptions, based on presenting symptoms, where there was no obvious separation of fragments. ${ }^{1-6}$ Cameron's cracked tooth syndrome described fractures that were not easily visible but the teeth responded

$1^{*}$ Specialist Registrar in Restorative Dentistry, Charles Clifford Dental Hospital, Wellesley Road, Sheffield, England S10 2TA

${ }^{*}$ Correspondence to: Simon G. S. Ellis

email:s.g.ellis@sheffield.ac.uk

REFEREED PAPER

Received 25.04.00; Accepted 12.09.00

(C) British Dental Journal 2001; 190: 424-428

\section{In brief}

- Tooth fractures should be considered as either complete or incomplete

- The depth, direction, tissues involved and the potential to progress are important management tissues for incomplete fractures

- A variety of presentations may occur

- Symptoms will vary according to the stage of incomplete fracture

painfully to cold or pressure applications and became necrotic despite an apparent healthy pulp and periodontium. In addition, there were often recurring patterns in different teeth in the same patient. ${ }^{7}$ When reviewing the literature in the late 1970s, Maxwell and Braly ${ }^{11}$ concluded that many authors ${ }^{1,6,7,10}$ were actually describing the same clinical entity. They advocated use of the umbrella term incomplete tooth fracture which had earlier appeared in $1957^{3}$ although its definitive origin remains elusive. Despite the introduction of further terms such as hairline fracture, incomplete crown-root fracture, split-root syndrome, enamel infraction, hairline tooth fracture, crown craze/crack, craze lines and tooth structure cracks, ${ }^{12-15}$ Luebke preferred to consider fractures as either complete or incomplete. He called this division the nature of tooth fracture and made appropriate definitions (Figs 1 and 2). ${ }^{16}$

\section{Presenting clinical features}

Most clinicians will have seen numerous complete tooth fractures such as the common cuspal fracture illustrated in Figure 3. In contrast, ITFs are characterised as having no loss or visible separation of tooth structure $^{5,11,15,16}$ and may be detected routinely during an examination or cavity

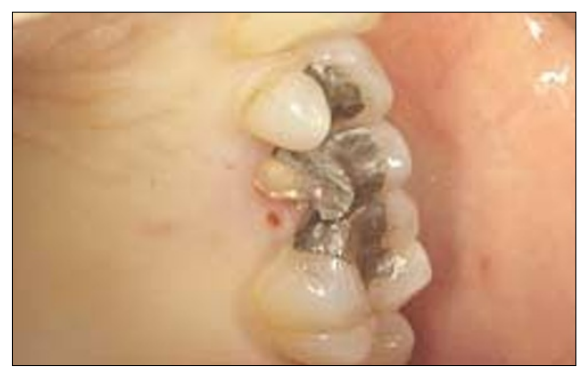

Fig. 3 A common example of a complete tooth fracture where the palatal cusp of a maxillary premolar, restored with a large MOD amalgam, is lost 


\begin{tabular}{|c|c|}
\hline Fig. I & $\begin{array}{l}\text { Chronological development of terms and, when clearly stated, definitions for } \\
\text { tooth fractures where there is no obvious separation of the fragments }\end{array}$ \\
\hline 1954 & Cuspal Fracture Odontalgia (Gibbs) ${ }^{\prime}$ - describes symptoms associated with ITFs \\
\hline 1954 & $\begin{array}{l}\text { Fissured Fracture (Thoma) }{ }^{2}-\text { 'a crack in the crown of the tooth. It may involve enamel } \\
\text { alone or both the enamel and dentine' }\end{array}$ \\
\hline 1957 & Incomplete Tooth Fracture (Ritchey, Mendenhall \& Orban) ${ }^{3}$ \\
\hline 1957 & $\begin{array}{l}\text { Fissural Fracture (Down) }{ }^{4} \text { - 'fractures involving enamel and dentine without loss of } \\
\text { tissue' }\end{array}$ \\
\hline 1961 & $\begin{array}{l}\text { Crack Lines (Sutton) }{ }^{5} \text { - 'a break in the continuity of the tooth revealed only by the } \\
\text { presence of a visible transverse line' }\end{array}$ \\
\hline 1962 & $\begin{array}{l}\text { Greenstick Fractures (Sutton) }{ }^{6} \text { _ 'a fracture line forms in a part of a tooth underlying a } \\
\text { cusp. The fractured part remains in place except when forced away from the central } \\
\text { sulcus by a lateral force sufficiently strong to produce bending of that part of the tooth } \\
\text { which is between the affected cusp and the root' }\end{array}$ \\
\hline 1964 & Cracked Tooth Syndrome (Cameron) ${ }^{7}$ — describes a triad of signs and symptoms of ITFs \\
\hline 1972 & Hairline Fracture (Wiebusch) 8 \\
\hline 1973 & Incomplete Crown-Root Fracture (Hiatt) ${ }^{9}$ \\
\hline 1976 & Split-Root Syndrome (Silvestri) 10 \\
\hline 1977 & $\begin{array}{l}\text { Incomplete Tooth Fracture (Maxwell \& Braly) II _ 'a fracture of tooth structure which } \\
\text { extends into dentine but in which the tooth remains grossly intact' }\end{array}$ \\
\hline 1981 & $\begin{array}{l}\text { Enamel Infraction (Andreasen) }{ }^{12} \text { _an incomplete fracture (crack) of the enamel without } \\
\text { loss of tooth substance' and 'lines in enamel which do not cross the amelodentinal junction' }\end{array}$ \\
\hline 1981 & Hairline Tooth Fracture (Caulfield) ${ }^{13}$ \\
\hline 1981 & Crown Craze/Crack (Johnson) ${ }^{14}$ _ 'injury ... of enamel without loss of tooth structure' \\
\hline 1983 & $\begin{array}{l}\text { Crack Lines, Craze Lines, Tooth Structure Cracks (Abou-Rass) } \\
\text { Tooth Structure Cracks - 'a line that breaks or splits the continuity of tooth dentinal } \\
\text { surface but does not perceptibly separate that surface' } \\
\text { Craze Lines - 'located in coronal enamel' }\end{array}$ \\
\hline 1984 & $\begin{array}{l}\text { Incomplete Tooth Fracture (Luebke) }{ }^{16} \text { - 'a demonstrable fracture but with no visible } \\
\text { separation of the segments along the plane of the fracture' }\end{array}$ \\
\hline
\end{tabular}

preparation or specifically included in differential diagnosis of pain (Figs 4-9). Visual detection may be difficult as Caufield's analysis of crack lines under a scanning electron microscope demonstrated, the width of the fracture plane can be less than $18 \mu .{ }^{13}$ Clinical detection depends on the length and width of the fracture, type of illumination (dental light or fibre-optic transillumination), operator working distance and the use of contrast media such as methylene blue, iodine and even dietary stains. $7,13,37$ Symptoms primarily arise from stimulation of the dentinal tubules following minute separation of the fracture or from an irreversible pulpits resulting from microleakage along the fracture

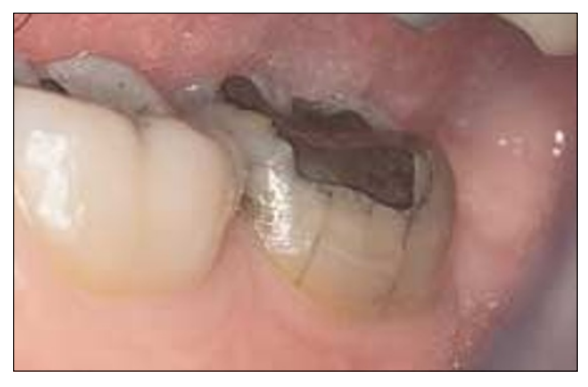

Fig. 5, 6 ITFs presenting in the axial enamel of opposing mandibular and maxillary molars around old amalgam restorations. The patient was having considerable pain, which was worse when chewing on the left posterior teeth. She freely admitted to and had notable signs of parafunctional activity

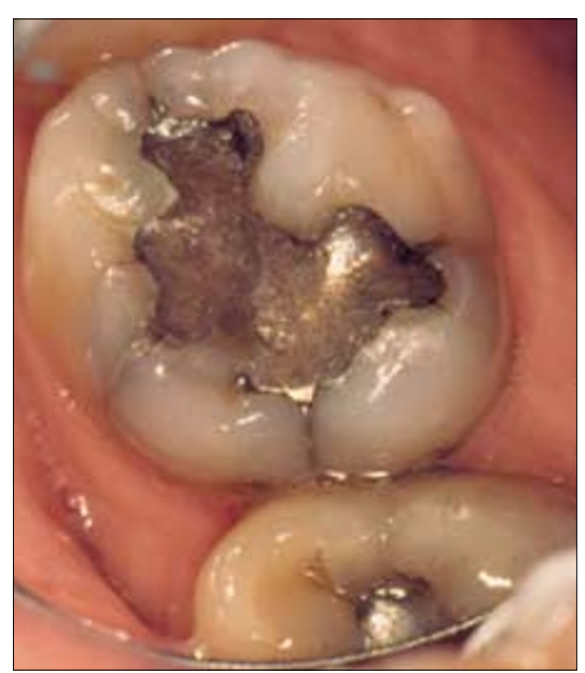



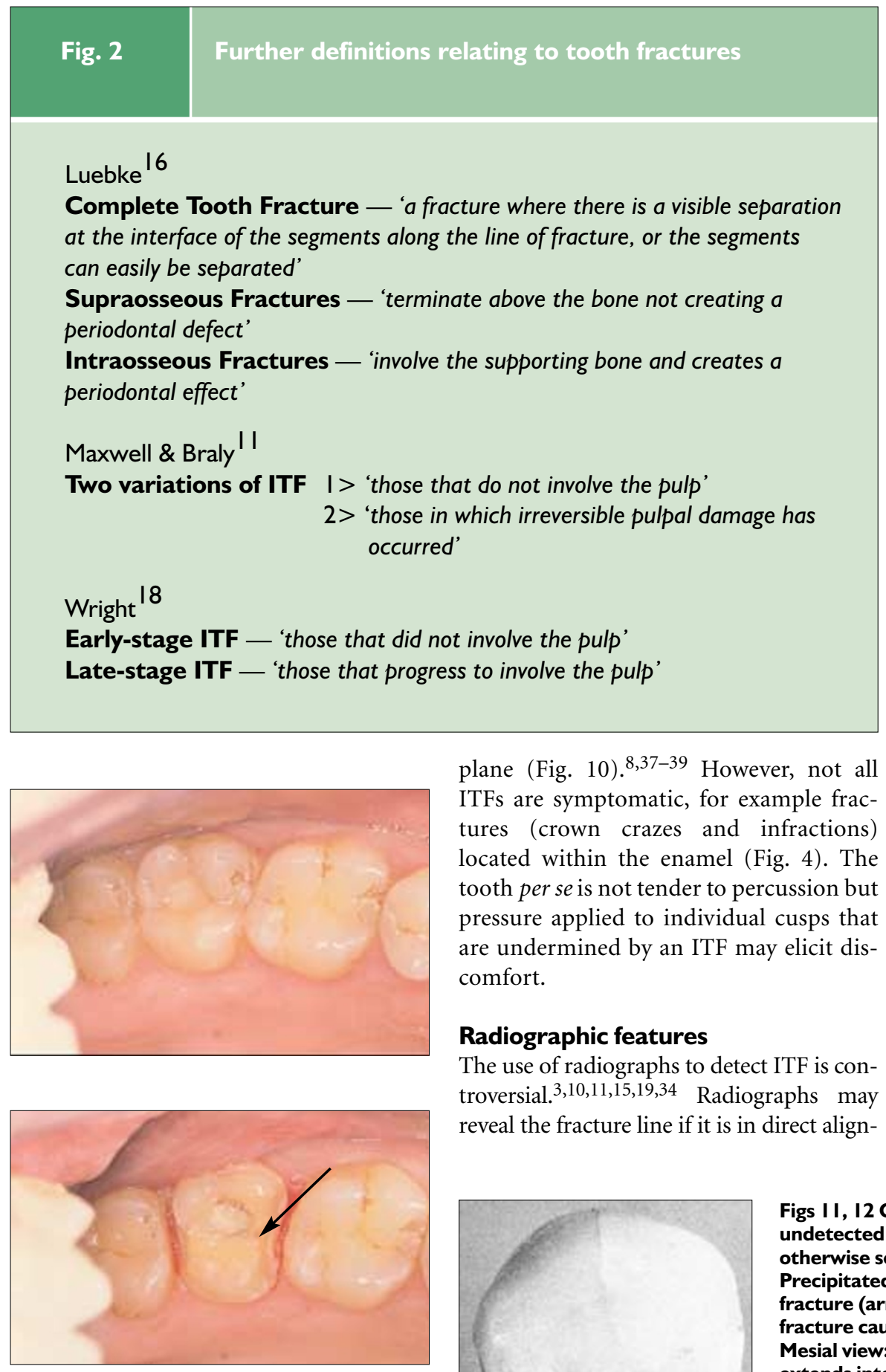

Fig. 7,8 Symptomatic ITF presenting in a maxillary molar which failed to settle with an occlusal glass ionomer restoration. An MOD onlay was prescribed to splint the tooth and prevent fracture plane propagation. Note the fracture plane is still present mesially (arrowed) even after significant tooth reduction

\section{Radiographic features}

The use of radiographs to detect ITF is controversial. $3,10,11,15,19,34$ Radiographs may reveal the fracture line if it is in direct alignbacteria

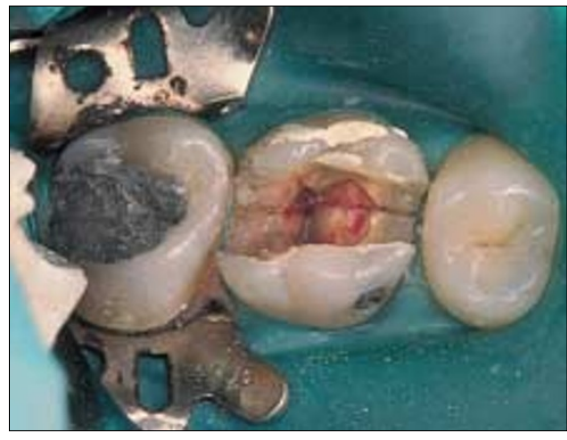

Fig. 9 An MOD vertical root fracture underneath an existing amalgam restoration

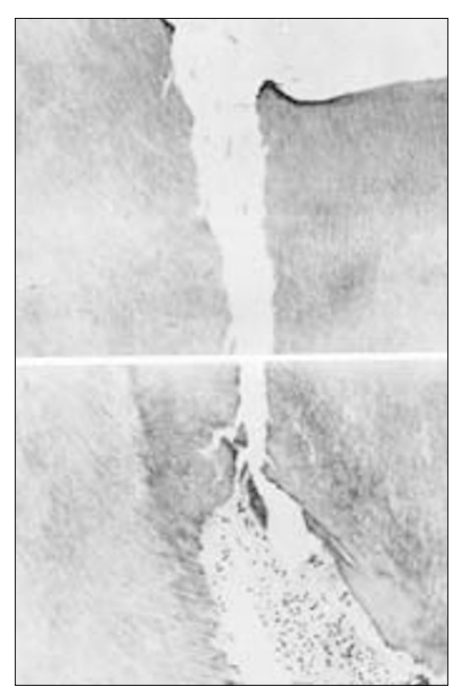

Fig. I 0 A photomicrograph of an undisclosed fracture from floor of cavity to the pulp. Inflammatory degeneration of the pulp is apparent

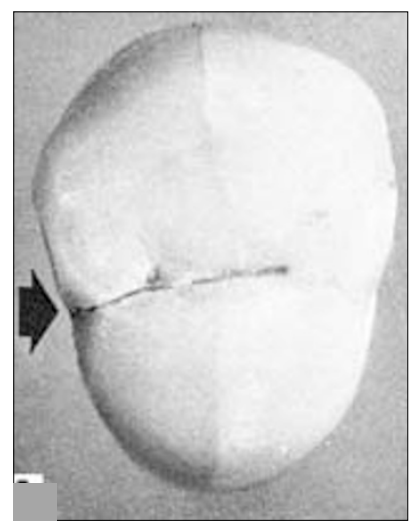

Figs I I, I 2 Occlusal view: an undetected fracture in otherwise sound premolar. Precipitated iodine shows fracture (arrow). (Buccolingual fracture caused by forceps). Mesial view: the fracture extends into pulp that has become necrotic from invading

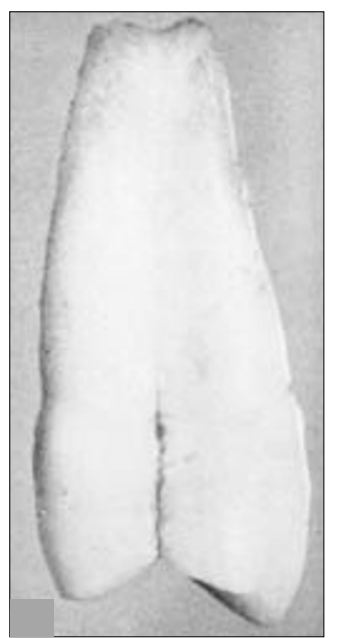




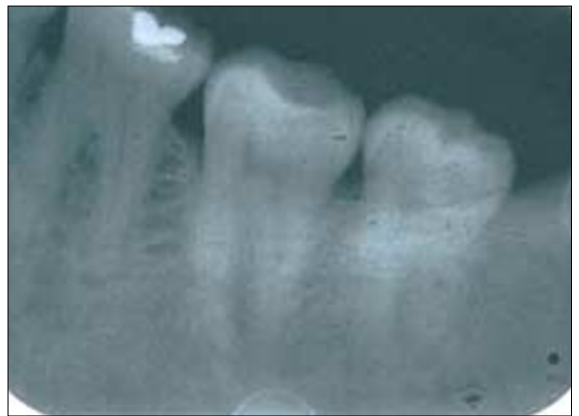

Fig. I 3 A radiograph of a vertical ITF in a minimally restored mandibular first molar. Periapical radiolucencies, which suggest apical pathology and pulp necrosis, are demonstrated

ment with the central rays but since many fractures run mesio-distally, or in some intermediate plane, alignment is not possible (Figs 11,12). ${ }^{8}$ The advantage of aligning in-vitro radiographs over clinical films has been demonstrated ${ }^{39}$ presumably because of the lack of contrast-reducing soft tissues. The sequelae of fractures will feature more frequently on radiographs than the fracture itself. Not uncommonly periapical radiolucencies indicative of pulp death are revealed (Fig. 13) whilst localised periodontal ligament and lamina dura abnormalities may suggest a fracture emerging on the root surface. Condensing osteitis which is associated with low-grade irritation has also been

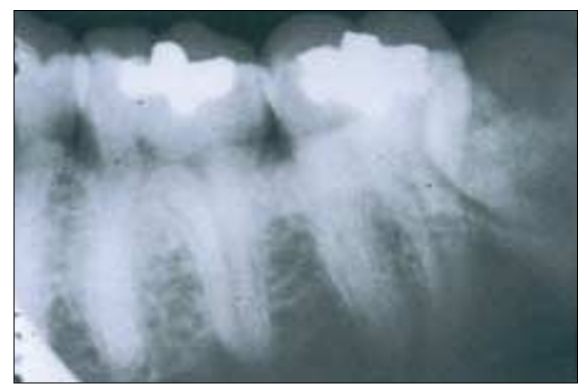

Figs I4-16 Periapical radiographs and colour slide of an oblique ITF progressing to a complete crown-root fracture. The patient had pain in the left mandibular molars and fracture lines were evident beneath the amalgam restoration when they were removed diagnostically. Figure 14 (top left) shows no evidence of the fracture. The second molar was extracted at the patient's request because of the severity of symptoms noted in the periapical region of teeth with ITF. ${ }^{10}$ However, care must be taken when examining the radiograph as artefacts on the film have been confused with fractures. ${ }^{40}$ The consensus is that clinical radiographs cannot reliably identify ITF but they are required to assess the periapical and periodontal status of teeth and any restorations present and to exclude other sources of pain/ discomfort ie root perforations or internal/ external resorption. ${ }^{9,15,16,19,29,34,37,41}$

\section{Patterns of fracture}

ITFs may involve a combination of crown and root structure and are notoriously difficult to treat because the depth and direction (horizontal, oblique or vertical) of the fracture plane cannot usually be clinically determined. These two factors (depth and direction) will influence:

- To what extent enamel and dentine are involved and whether the pulp chamber is breached and

- If the fracture plane is 'on course' to penetrate the external root surface.

Fractures involving the pulp were recognised as early as $1954,{ }^{2}$ and, as illustrated in Figure 10, have endodontic consequences. Surveys have concluded that ITFs were present in up to $20 \%$ of endodontic referrals and to account for the healthy and diseased
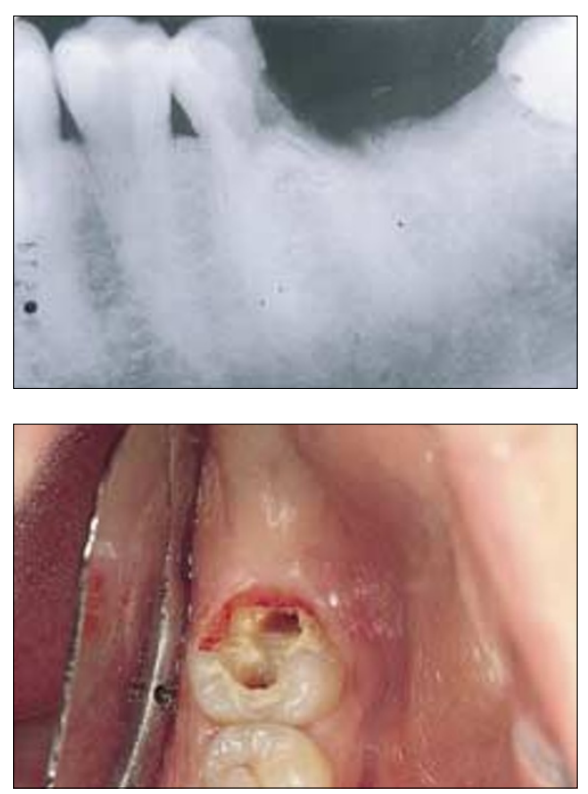

pulp status, two variations of ITF were proposed (Fig. 2). ${ }^{11,18}$ When the fracture communicates with the external root surface microleakage produces localised periodontal repercusions. ${ }^{9,29,31,39}$ Luebke recognised this with his protocol for the periodontal management of supra- and intra-osseous incomplete fractures (Fig. 2) whilst others have described general principles for managing periodontal defects. ${ }^{16,28,32}$ Oblique incomplete crown-root fractures which result in a periodontal defect and complicate the restorative rehabilitation are, however, preferable to vertical root fractures which have a poorer prognosis (Fig. 9).

\section{Natural history}

Another important feature of ITFs, namely progression, was highlighted by Wright and led to the definition of early- and late-stage fractures (Fig. 2). ${ }^{19} \mathrm{He}$ considered that ITFs of the crown may propagate obliquely or vertically whereas those originating in the root may progress occlusally, apically or in both directions. Previously, Abou-Rass had similar thoughts. He described structural cracks which 'extend into dentine' and, whilst differentiating them from craze lines 'located within coronal enamel', considered cracks a precursor to (complete) tooth fracture. ${ }^{15}$ The progression of an incomplete to a complete fracture is illustrated in Figures 14-16. Data gathered from an in-vivo study and relevant literature has shown ITF to be statistically more prevalent in older age groups compared with complete tooth fractures which presented over a wide age range. ${ }^{35,36}$ Whilst the aetiology of ITFs is multi-factorial ${ }^{17}$ these findings do suggest a time-related progression throughout life.

\section{Proposal for a new definition}

It is evident that many authors have approached ITF from different perspectives but none of the definitions can be universally applied. As the fracture pattern cannot be reliably ascertained by examination it may be more prudent to have a definition that reflects the multitude of signs and symptoms, fracture anatomy and tooth prognosis. The depth, direction, tissues involved, potential to progress and the fact that there is no visible separation of tooth 
structure are important issues that enable ITF to be considered a four-dimensional entity. In light of these, the following revised definition is proposed: 'a fracture plane of unknown depth and direction passing through tooth structure that, if not already involving, may progress to communicate with the pulp and/or periodontal ligament'.

Clinicians would find it helpful to consider the elements of this definition when diagnosing and planning the management of teeth with incomplete fractures.

\section{Summary}

This paper reviews the evolution of incomplete tooth fracture nomenclature, discusses the clinical and radiographic features and proposes a definition which is representative of the clinical issues. Notable management and aetiological literature is also highlighted as a reference source.

The author would like to thank Professor J F McCord (Unit of Prosthodontics, University Dental Hospital of Manchester), Raj Joshi (Consultant in Restorative Dentistry, Charles Clifford Dental Hospital, Sheffield) and Keith Horner (Senior Lecturer in Dental and Maxillofacial Radiology, University Dental Hospital of Manchester) for their helpful comments and advice in preparing this article. Figure 9 is courtesy of Ian Harris (Consultant in Restorative Dentistry, Charles Clifford Dental Hospital, Sheffield). Figures 10-12 are the work of Dr D H Glick and Dr H Stanley and taken along with the accompanying text from 3365 of the 4th edition of Endodontics (1994) by J.I. Ingle and L.K. Bakland and reproduced with permission of the publishers Lippincott Williams and Wilkins. Figures 3-9 and 13-16 were produced with the assistance of the Radiology Department of the University Dental Hospital of Manchester and the Department of Medical Illustration at the Royal Hallamshire Hospital, Sheffield.

1 Gibbs J W. Cuspal fracture odontalgia. Dent Dig 1954; 60: 158-160.

2 Thoma K H. Oral pathology 4th edn, St. Louis: Mosby, 1954; p220.

3 Ritchey B, Mendenhall R, Orban B. Pulpitis resulting from incomplete tooth fracture. Oral Surg 1957; 10: 665-670.
4 Down C H. The treatment of permanent incisor teeth of children following traumatic injury. Aust Dent J 1957; 2: 9.

5 Sutton P R N. Transverse crack lines in permanent incisors of polynesians. Aust Dent 1961; 6: 144-50.

6 Sutton P R N. Greenstick fracture of the tooth crown. Br Dent J 1962; 112: 362-363.

7 Cameron C E. Cracked-tooth syndrome. J Am Dent Assoc 1964; 68: 405-411.

8 Wiebusch F B. Hairline fracture of a cusp: Report of case. J Can Dent Assoc 1972; 5: 192194.

9 Hiatt W H. Incomplete crown-root fracture in pulpal-periodontal disease. J Periodontol 1973; 44: 369-79.

10 Silvestri A R. The undiagnosed split-root syndrome. J Am Dent Ass 1976; 92: 930.

11 Maxwell E H, Braly B V. Incomplete tooth fracture: Prediction and prevention. J Calif Dent Assoc 1977; 5: 51-55.

12 Andreasen J O. Traumatic injuries of the teeth. 2nd edn, Copenhagen: Munksgaard, 1981; p19.

13 Caufield J B. Hairline tooth fracture: A clinical case report. JAm Dent Assoc 1981; 102: 501502.

14 Johnson R. Descriptive classification of traumatic injuries to the teeth and supporting structures. J Am Dent Assoc 1981; 102: 195-197.

15 Abou-Rass M. Crack lines: The precursors of tooth fractures - their diagnosis and treatment. Quintessence Int 1983; 4: 437-447.

16 Luebke R G. Vertical crown-root fractures in posterior teeth. Dent Clinic North Am 1984; 28 : 883-894.

17 Ellis S G S, McCord J F, Burke F J T. Predisposing and contributing factors for complete and incomplete tooth fractures. Dent Update 1999; 26: 150-158.

18 Braly B V, Maxwell E H. Potential for tooth fracture in restorative dentistry. J Prosthet Dent 1981; 45: 411-414.

19 Wright E F. Diagnosis, treatment and prevention of incomplete tooth fractures. Gen Dent 1992; 40: 390-396.

20 Woodcock J A. Diagnosis and management of the fractured tooth: 1. Diagnosis. Dent Update 1991; 18: 283-288.

21 Woodcock J A. Diagnosis and management of the cracked tooth: 2 . Management. Dent Update 1991; 18: 336-340.

22 Silvestri A R, Singh I S. Treatment rationale of fractured posterior teeth. J Am Dent Assoc 1978; 97: 806-810.

23 Clark L L, Caughman W F. Restorative treatment for the cracked tooth. Oper Dent 1984; 9: 136-142.
24 Malcolm P J, Hood J A A. The effect of cast restorations in reducing cusp flexibility in restored teeth. J Dent Res 1977; 56: D207 (Abstract No. 67).

25 Burke F J T, Wilson N H F, Watts D C. The effect of cuspal coverage on the fracture resistance of teeth restored with indirect composite resin restorations. Quintessence Int 1993; 24: 875-880.

26 Macpherson L C, Smith B G N. Reinforcement of weakened cusps by adhesive restorative materials: an in-vitro study. Br Dent J 1995; 178: 341-344.

27 Gutmann J L, Rakusin H. Endodontic and restorative management of incompletely fractured molar teeth. Int Endo J 1994; 27: 343 348.

28 Schneider A R, Binder H. Periodontal considerations relevant to treating the fractured tooth. J Prosthet Dent 1984; 51: 624627.

29 Polson A M. Periodontal destruction associated with vertical root fracture - Report of four cases. J Periodontol 1977; 48: 27-32.

30 Pitts D L, Natkin E. Diagnosis and treatment of vertical root fractures. J Endod 1983; 9: 338346.

31 Joffe E. Management of vertical root fracture in endodontically treated teeth. The New York State Journal 1992; 58: 25-27.

32 Heithersay G S, Moule A J. Anterior subgingival fractures: A review of treatment alternatives. Aust Dent J 1982; 27: 368-376

33 McCord J F, Harvie H. An alternative treatment of anterior teeth fractured beneath the gingival margin. Br Dent J 1984; 157: 320-322.

34 Fisher F J. Toothache and cracked cusps. $\mathrm{Br}$ Dent J 1982; 153: 298-300.

35 Ellis S G S. Tooth fractures presenting in university students attending an emergency dental service. MSc Thesis, University of Manchester, 1997.

36 Ellis S G S, Mcfarlane T V, McCord J F. Influence of patient age on the nature of tooth fracture. J Prosthet Dent 1999; 82: 226-230.

37 Rosen H. Cracked tooth syndrome. J Prosthet Dent 1982; 47: 36-43.

38 Swepston J H, Miller A W. The incompletely fractured tooth. J Prosthet Dent 1986; 55 : 413-416.

39 Ingle J I, Bakland L K. Endodontics. 4th edn, Philadelphia: Williams and Wilkins, 1994; p364-5,537-8.

40 Shanmuhasuntharam P. Radiographic artefact mimicking root fracture. Oral Surg Oral Med Oral Pathol 1993; 76: 131.

41 Dental Protection Society. Dental News. November 1999, Issue 20;p11. 